3. From: (Originating Organization)

Systemsfluor Daniel Hanford

6. Design Authority/Design Agent/Cog. Engr.:

DAWN E. ADAMS

HANF6800

1. EDT

N/A

$\mathrm{N} / \mathrm{A}$

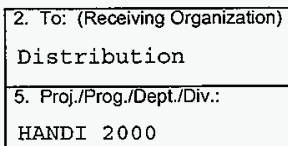

11. Receiver Remarks:

11A. Design Baseline Document? $\square$ Yes $\square$ No
4. Related EDT No::

7. Purchase Order No:

9. Equip./Component No.:

$\mathrm{N} / \mathrm{A}$

10. System/Bldg./Facility:

$\mathrm{N} / \mathrm{A}$

12. Major Assm. Dwg. No.:

N/A

13. Permit/Permit Application No:

N/A

14. Required Response Date:

$\mathrm{N} / \mathrm{A}$

(F)

DATA TRANSMITTED

15.

\begin{tabular}{|c|c|}
\hline $\begin{array}{c}\text { (C) Sheet } \\
\text { No. }\end{array}$ & (D) Rev. \\
No.
\end{tabular}

(E) Title or Description of Data Transmitted

(F)

(G)

(H)

\begin{tabular}{l|l|l|}
\hline Approval Reason & Origi- & Receiv-
\end{tabular}

(A)

Nom

(B) Document/Drawing No.

\begin{tabular}{|l|l}
\hline$N / A$ & 0 \\
\hline
\end{tabular}

RELEASE AND UPGRADE

PROCEDURE FOR HANDI 2000

BUSINESS MANAGEMENT SYSTEM

$\mathrm{M}$

16.

\begin{tabular}{|c|l|}
\hline Approval Designator (F) & \\
\hline E, S, Q, D OR N/A & 1. Approval \\
(See WHC-CM-3-5, & 2. Release \\
Sec. 12.7) & 3. Information \\
\hline
\end{tabular}

17.
$\mathrm{N} / \mathrm{A}$

(K) Signature

Reason
4. Review

Review

. Dist. (Receipt Acknow. Required)

KEY

(See Approval Designator for required signatures)
(L) Date
(M) MSIN \begin{tabular}{c|c} 
Rea- \\
Ran \\
son
\end{tabular} Disp.
(J) Name
(K) Signature
(L) Date
(M) MSIN

Disposition $(\mathrm{H})$ \& (l)

4. Reviewed no/comment

5. Reviewed w/comment

6 . Receipt acknowledged





HANDI 2000 BUSINESS MANAGEMENT SYSTEM

\author{
Diane Wilson \\ MSN G1-22 \\ Richland, WA 99352 \\ U.S. Department of Energy Contract DE-AC06-96RL13200

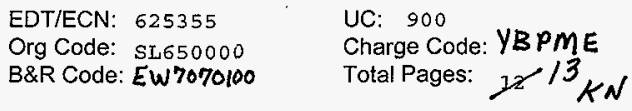

Key Words: H2K, BMS, HANDI 2000, BUSINESS MANAGEMENT SYSTEM, RELEASE, UPGRADE

Abstract: The Hanford Data Integration 2000 (BANDI 2000) Project will result in an integrated and comprehensive set of functional applications containing core information necessary to support the Project Hanford Management Contract (PHMC). It is based on the Commercial-Off-The-Shelf (COTS) product solution with commercially proven business processes. The COTS product solution set, of PassPort (PP) and Peoplesoft (PS) software, supports finance, supply and chemical management/Material safe

TRADEMARK DISCLAIMER. Reference herein to any specific commercial product, process, or service by trade name, trademark, manufacturer, or otherwise, does not necessarily constitute or imply its endorsement, recommendation, or favoring by the United States Government or any agency thereof or its contractors or subcontractors.

Printed in the United States of America. To obtain copies of this document, contact: Document Control Services, P.O. Box 950, Mailstop H6-08, Richland WA 99352, Phone (509) 372-2420; Fax (509) 376-4989.

PassPort is a trademark of Indus Corp. PeopleSoft is a trademark of Indus corp. Unix is a trademark of $x / 0 p e n ~ C o . ~ L t d$. Portal is a trademark of Indus Corp.
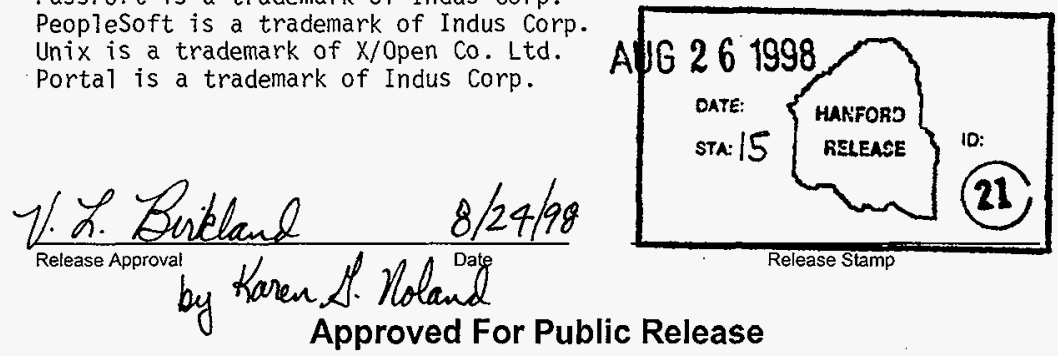


\section{RELEASE AND UPGRADE PROCEDURE}

FOR

HANDI 2000

\section{BUSINESS MANAGEMENT SYSTEM}

Prepared by: Sandra Evosevich, LMSI Software Engineer

Prepated for: Fluor Daniel Hanford

Approved by:

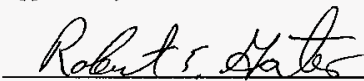

Robert E. Gates, H2K Project Director

Steve Manley, FDH/CIO Manager

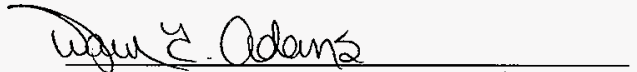

Dawn E. Adams, BMS Project Manager

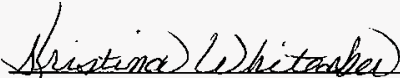

Kristina Whiteaker, NDUS Project Manager

$\rho B$ traares.

Phillip B. (Brian) Isaacs, LMSI Project Manager

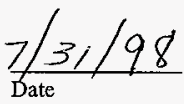

$7 \frac{8 / 29 / 98}{\text { Date }}$
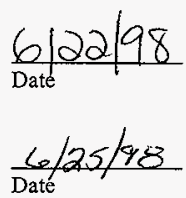

$\frac{6 / 15 / 98}{\text { Date }}$ 


\section{TABLE OF CONTENTS}

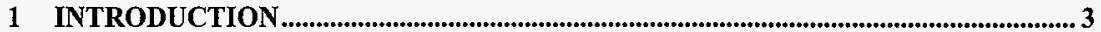



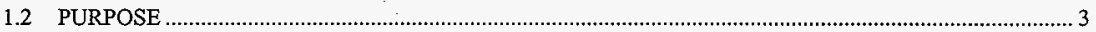

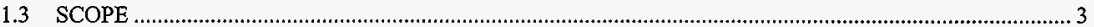

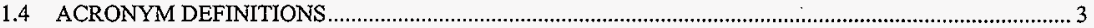

1.5 TERMS …

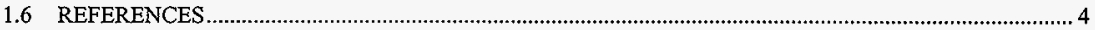

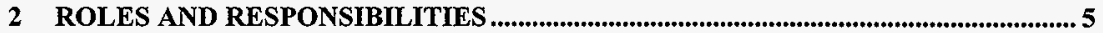

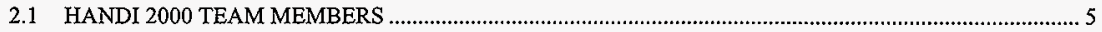

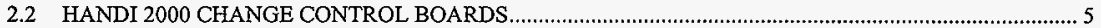

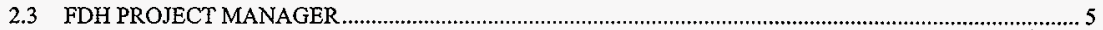

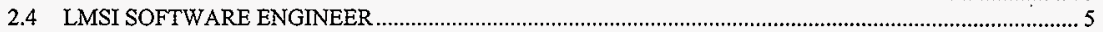

2.5 LMSI DATABASE ADMINISTRATOR …

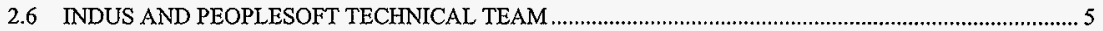

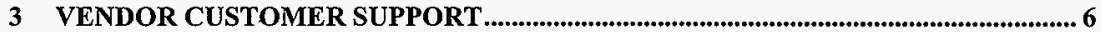

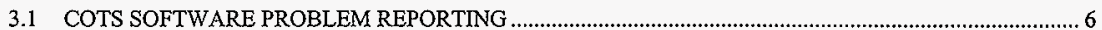

4 ANALYSIS OF RELEASES/UPGRADES ........................................................................ 7

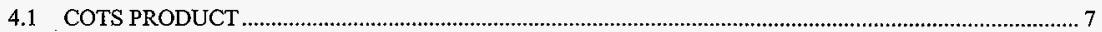

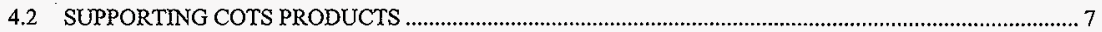

5 COTS PRODUCT STANDARD MAINTENANCE RELEASE....................................8

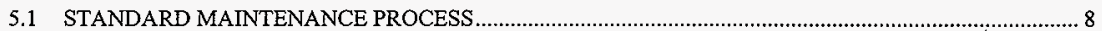

6 COTS PRODUCT PATCH MAINTENANCE RELEASE..........................................9

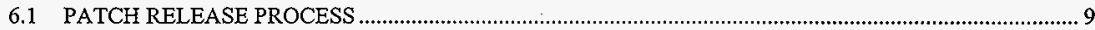

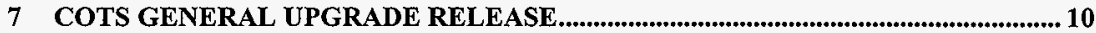

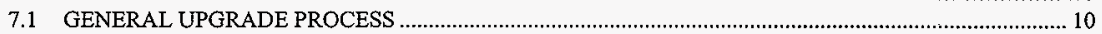

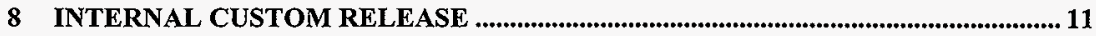

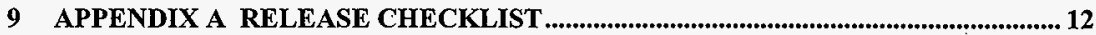




\section{INTRODUCTION}

\subsection{OVERVIEW}

The Hanford Data Integration 2000 (HANDI 2000) Project will result in an integrated and comprehensive set of functional applications containing core information necessary to support the Project Hanford Management Contract (PHMC). It is based on the Commercial-Off-The-Shelf (COTS) product solution with commercially proven business processes. The COTS product solution set, of PassPort (PP) and PeopleSoft (PS) software, supports finance, supply and chemical management/Material Safety Data Sheet (MSDS), human resources, and payroll activities under the current PHMC direction. The PP software is an integrated application for Accounts Payable, Contract Management, Inventory Management, Purchasing and MSDS. The PS software is an integrated application for Projects, General Ledger, Human Resources/Training, Payroll, and Base Benefits. This set of software constitutes the Business Management System (BMS) and MSDS, a subset of the HANDI 2000 suite of systems.

\subsection{PURPOSE}

The Release and Upgrade Procedure (RUP) provides guidelines for implementing HAND 2000 software releases and upgrades. The intent is to facilitate the migration of software modifications, software releases, maintenance releases, and emergency product fixes into the baseline and production environment. In addition, this document will describe the process for COTS software problem reporting. This RUP becomes effective as of this document's acceptance and will provide guidance through implementation efforts and, as a "living document", will support the operation and maintenance of the HANDI 2000 systems.

\subsection{SCOPE}

The RUP will address the HANDI 2000 procedures for COTS standard maintenance, product fix maintenance, general upgrade maintenance, and custom system change releases. In addition, this document will describe the process for reporting vendor software problems.

\subsection{ACRONYM DEFINITIONS}

\begin{tabular}{|l|l|}
\hline \multicolumn{1}{|c|}{ Acronym } & \multicolumn{1}{c|}{ Definition } \\
\hline BMS & Business Management System \\
\hline COTS & Commercial-Off-The-Shelf software \\
\hline FDH & Fluor Daniel Hanford \\
\hline HAND 2000 & Hanford Data Integration 2000 \\
\hline INDUS & Indus International Incorporated \\
\hline LMSI & Lockheed Martin Services, Inc \\
\hline MSDS & Material Safety Data Sheet \\
\hline PP & PassPort software \\
\hline PS & PeopleSoft software \\
\hline RUP & Release and Upgrade Procedure \\
\hline
\end{tabular}

\subsection{TERMS}

General Upgrade Release: A major software release (e.g. Release 6.0). The upgrade contains all prior product standard maintenance releases and patch maintenance releases, plus new products, product enhancements, and database changes. The delivery media is tape, diskette, or $\mathrm{CD}$.

Internal Custom Release: An internally developed software release usually consists of a grouping or block point of changes (e.g., HPS7.0.1a). 
Patch Maintenance Release: A software product fix for reported problems (e.g. PassPort - Package Number: 00695, Platform: UNIX \& MVS, Product PORTAL 197 Client, Release 6.0.1 or PeopleSoft - Report ID: R-TMCCAMY2F63F, Product Line: Financials, Product: Projects, Product Line Release: Financial 6.0, Platforms: All). The delivery media is the Internet.

Standard Maintenance Release: A minor software product release that is issued between major upgrade releases (e.g., Release 6.1.0). This release contains only modules changed since the last general upgrade release. The delivery media is tape, diskette, or $\mathrm{CD}$.

\subsection{REFERENCES}

HNF-2484

HNF-2583

FDH Contracts
Region and Database Management Plan

Software Configuration Management Plan

MJC-SBB-A346022, 09/10/97 and G956631J73, 03/31/98 


\section{ROLES AND RESPONSIBILITIES}

\subsection{HANDI 2000 TEAM MEMBERS}

Includes Lockheed Martin Services, Incorporated (LMSI) Software Engineer, LMSI Database Administrator, LMSI Operations, and Fluor Daniel Hanford (FDH) Project Manager or Integration Vendor, where appropriate.

- Report COTS problems to the appropriate vendor HelpDesk

- Log and track the COTS reported problem and resolution

- Prioritize the reported COTS problem

- Pexform patch fix, release and upgrade evaluations

\subsection{HANDI 2000 CHANGE CONTROL BOARDS}

- Review and approve or disapprove system releases and upgrades. Reference HNF-2583, Software Configuration Management Plan

\subsection{FDH PROJECT MANAGER}

- Ensure the System Change Request process is followed

\subsection{LMSI SOFTWARE ENGINEER}

- Identify and evaluate patches on the Internet for content, applicability for the installation and other requirements such as prerequisites to be applied

- Receive standard maintenance or general maintenance upgrade software

- Perform patch maintenance, standard release maintenance and upgrade maintenance processes

\subsection{LMSI DATABASE ADMUNISTRATOR}

- Loads releases and upgrades on appropriate regions or databases for testing

- Migrates releases and upgrades to appropriate regions or databases for production

\subsection{INDUS AND PEOPLESOFT TECHNICAL TEAM}

- Provide product support HelpDesks for customer problem reporting

- Resolve reported software problems through a patch fix, standard maintenance release, or upgrade release 


\section{VENDOR CUSTOMER SUPPORT}

PassPort and PeopleSoft maintain a Product Support program that provides customer support using the PassPort and PeopleSoft HelpDesks. Problems reported on COTS software result in standard maintenance releases, product fix maintenance, and general upgrade maintenance. The HANDI 2000 team members will report the identified software problems to the appropriate vendor HelpDesk.

\subsection{COTS SOFTWARE PROBLEM REPORTING}

The problem reporting process is as following:

- Identify the problem - The HANDI 2000 team member reporting the software problem will collect a step by step occurrence that identified the problem and verify that the problem is software related. Where possible, identify the objects causing the problem. The reporter will attempt to recreate the problem and collect any possible supporting documentation such as prints of the panels, data, or abend logs.

- Log the problem - The reporter will log, update and track the problem on an automated tracking system.

- Prioritize the item - The HANDI 2000 team members will prioritize problem issues. The most significant prioritization is standard versus emergency maintenance. Appropriate risk classifications are 1) high risk impacts the business process, or system functionality, or data integrity; 2) moderate risk - a work around is available; 3) low risk - cosmetic fix or a "nice to have" enhancement.

- Track the problem - When the problem has been logged and reported to the vendor HelpDesk, the problem will be tracked until the resolution is received, tested and implemented. The item will then be logged as closed. 


\section{ANALYSIS OF RELEASES/UPGRADES}

\subsection{COTS PRODUCT}

The HANDI 2000 team members will perform an installation impact analysis for each product patch fix, standard maintenance, and general upgrade release to determine the effect on business processes, interfaces and other supporting COTS and customized software and hardware. Consideration must be given to items such as additional training of personnel, possible replacement of existing software due to product customization or enhancement, effects on internal and external interfaces, and other supporting COTS software and hardware. Production timing issues, such as year-end closing, must be addressed. In addition, the evaluation must consider the new functionality and timing of the new release versus the next future release. It may be prudent to await the release of the next major upgrade. There must be an approval and coordination, for releases that affect integration user communities, before testing and installation can proceed.

\subsection{SUPPORTING COTS PRODUCTS}

Releases and upgrades required for supporting COTS software and hardware, such as Database Management Systems and Operation Systems, must also be evaluated for impact to COTS support groups, software, and hardware. Consideration must be given to items such as version compatibility, platform change impact upon resident systems, interfacing systems/platforms, etc. There must be an approval and coordination from all affected integration user communities before testing and installation can proceed. 


\section{COTS PRODUCT STANDARD MAINTENANCE RELEASE}

Per the COTS maintenance contract agreement, the product standard maintenance releases, including the seven yearly PeopleSoft Tax Releases, will be delivered to the appropriate LMSI software engineer. Vendor standard maintenance releases will be provided throughout the calendar year. The standard maintenance release contains program modifications for problems reported to the HelpDesk, including all emergency product fixes and modules changed since the last delivery of software. The maintenance release tapes, diskettes, or CDs contain all modules for the product, program enhancements, or database changes, but installs only the changed objects. Maintenance release installation instructions as well as a Maintenance Release Guide are provided with each delivery. The Maintenance Release Guide provides, by product, a description of all problems resolved and the names of the changed objects. The installation instructions are tailored for the specific maintenance release and provide details on unloading the media (tapes, diskettes, or CDs) and performing any updates to messages, menus and/or codes.

According to the FDH Software Maintenance Contracts (Reference FDH Contracts MJC-SBB-A346022, 09/10/97 and $G 956631 J 73,03 / 31 / 98$ ), there is a specified timeframe for software support between releases. The HANDI 2000 team members will evaluate, test, and obtain approval from the HANDI 2000 Change Control Boards, to implement the product within this timeframe, unless a new contract agreement is negotiated. If indicated by the vendor, product maintenance releases should be implemented sequentially since releases may build upon the most current production version of the vendor products. Each standard maintenance release will require a Release Test Plan and follow the System Change Request process. Reference HNF-2583, Software Configuration Management Plan

The releases will be tracked on an automated tracking system.

NOTE: PeopleSoft software support information is available on the Internet, PeopleSoft Customer Connection page www4.peoplesoft.com/ce under Documentation $>$ Continuous Documentation- $>$ PeopleBooks by Category $>$ Product Deliverables Update.

\subsection{STANDARD MAINTENANCE PROCESS}

The following are steps in addition to the standard maintenance installation instructions.

- Execute the maintenance release install scripts.

- Identify any components in the maintenance release, which also appear in client-maintained lists of objects modified in the course of customizing PassPort or PeopleSoft. If any objects appear on both lists, the changes to both objects must be analyzed and merged (if possible) to form a version of the object that includes both PassPort or PeopleSoft maintenance changes and the client's custom changes.

- When no tables are modified or no new products are delivered on a maintenance release, installing the release can proceed as a straight forward migration exercise from the maintenance release directories populated at installation; migrate each object to its Acceptance Region or Test Database counter-part directory.

- When tables have been modified (e.g., Release 5.1.0), the conversion of data in the older version of the table must be assessed before the execution of the new "ddl" source statements via the PassPort tool "dftbgen" or the PeopleSoft Application tool.

- Re-create any panels delivered in the object directory of the maintenance media.

- Recompile any necessary $\mathrm{COBOL}$ programs for both the application and database servers.

- Load the upgrade into the appropriate testing region or database. After testing is complete, migrate the release to the appropriate regions or databases. Reference HNF-2484, Region and Database Management Plan. 


\section{COTS PRODUCT PATCH MAINTENANCE RELEASE}

When a problem has been reported to the vendor HelpDesk, and the appropriate INDUS or PeopleSoft technical team is able to recreate the problem, vendor resources will be immediately assigned to resolve the issue. When the 'Product Fix' (patch) is complete, the customer will receive the solution under the 'Product Fix' maintenance delivery system. Delivery of the patch fix, for PP and PS is only available through the Internet. The INDUS PP home page is www.indusworld.com. The Product fixes are located under the Support, Carenet for PassPort section of the INDUS home page. The PeopleSoft Product fixes are located in the Customer Connection page whww4.peoplesoft.com/cc. Normally, on a weekly basis, the LMSI software engineer will identify the appropriate patches available on the Internet to download for the HANDI 2000 team members' analysis.

The testing and implementation process is basically the same as described in Section 5, COTS Product Standard Maintenance Release. The differences are the media on which the patch is received, the urgency and timing of the problem identification, logging, prioritization, reporting and tracking. The patches will be tracked on the "Patches and Fixes" Microsoft Access database.

\subsection{PATCH RELEASE PROCESS}

- After the patch on the Internet is identified, an evaluation is performed for content, applicability for the installation and other requirements such as prerequisites to be applied. Many fixes build on functionality of other fixes and will not work properly if not installed in the correct order.

- Download or save the necessary attached files to a network accessible directory, and ensure all files are downloaded.

- Print the associated documentation and check the documentation's list of necessary files against the downloaded. Download any missing files to complete the fix package.

- Review the Installation Instructions. This document provides additional guidelines for the placing of files in default directories and other valuable instructions pertaining to installation fixes.

- Recompile any necessary $\mathrm{COBOL}$ programs for both the application and database servers.

- Load the patch fix into the appropriate region/database for testing. After testing is complete, migrate the patch fix to the appropriate regions or databases. Reference HNF-2484, Region and Database Management Plan. 


\section{COTS GENERAL UPGRADE RELEASE}

COTS general upgrade releases contain all prior product maintenance and product fix modifications, plus new products, product enhancements and database changes. A General Upgrade Release Guide is provided with each delivery. The installation instructions are tailored for the specific upgrade release and provides details on unloading the media (tapes, diskettes, or CDs) and performing any updates to messages, menus and/or codes.

According to the FDH Software Maintenance Contracts (Reference FDH Contracts MJC-SBB-A346022, 09/10/97 and $G 956631 / 773,03 / 31 / 98$ ), there is a specified timeframe for software support between releases. The HANDI 2000 team members will evaluate, test, and obtain approval from the HANDI 2000 Change Control Boards, to implement the product within this timeframe, unless a new contract agreement is negotiated. If indicated by the vendor, product maintenance releases should be implemented sequentially since releases may build upon the most current production version of the vendor products. Each general upgrade release will require a Release Test Plan and follow the System Change Request process. Reference HNF-2583, Software Configuration Management Plan

The releases will be noted on an automated tracking system.

NOTE: PeopleSoft software support information is available on the Internet, PeopleSoft Customer Connection page www4.peoplesoft.com/ce under Documentation->Continuous Documentation->PeopleBooks by Category->Product Deliverables Update.

\subsection{GENERAL UPGRADE PROCESS}

A full upgrade release, of vendor software, requires considerable planning. Relative to a standard maintenance release, the volume of objects to be installed in a full upgrade release is much larger and the task of successfully establishing a new release in a test environment is more complicated. Apart from the tasks documented in the install guide, the following critical issues need to be addressed:

- Presuming a wholly new instance is to be established with one or more existing instances and will require planning and acquisition of sufficient disk space.

- If any customization objects have been completed, merging these modified objects is a complex task requiring careful planning. The specific customization attribute must be compared to the new release attribute to analyze the affects of applying the change to the new object. PeopleSoft will certify the upgrade as being PeopleSoft compliant.

- When tables have been modified (e.g., Release 6.0), the conversion of data in the older version of the table must be assessed before the execution of the new "ddl" source statements yia the PassPort tool "dftbgen" or the PeopleSoft Application tool.

- Load the upgrade into the appropriate region or database for testing. After testing is complete the release will be migrated to the appropriate regions or databases. Reference HNF-2484, Region and Database Management Plan. 


\section{INTERNAL CUSTOM RELEASE}

An internal custom release refers to, but is not limited to activities such as: customization, enhancements, corrections of logic defects, and application or system optimization changes for the primary COTS product or other supporting COTS products and custom developed software. As directed by the FDH Project Manager and the HANDI 2000 Change Control Boards, the LMSI software engineer and database administrator will document, track, test and implement any custom releases. It is recommended that a release should consist of a grouping or block point of changes. Each custom release will follow the System Change Request process and will require a Release Test Plan. Reference HNF-2583, Software Configuration Management Plan. 


\section{APPENDIX A RELEASE CHECKLIST}

The Checklist consists of items to be addressed when preparing a Release Test Plan. This list may not be allinclusive.

- Identify work scope

- Develop schedule

- Ensure for system upgrade support (technical and functional)

- Identify all primary COTS software baseline elements

- Identify all tailoring and customization elements outside the COTS baseline elements

- Identify all operating system elements

- Identify all client workstation system elements

- Identify all supporting secondary COTS software elements

- Identify all network system software elements

- Identify all legacy systems elements

- Identify all integrated systems elements that will be impacted

- Identify the test environment

- If appropriate, identify data migration approach

- Identify product, release fixes

- Identify and prepare test scripts including integrated features and new business processes

- Identify Acceptance Criteria

- Provide for Customer Signature Approval 